\title{
ВЛИЯНИЕ ОСУШЕНИЯ НА РЕЖИМ РЕЧНОГО СТОКА в УСлОВИЯХ ЭСТОНСКОЙ ССР
}

\author{
К. Т. Хоммик
}

Расширение кормовой базы и увеличение объема сельскохозяйственной продукции тесно связано с проведением мелиоративных работ, обеспечивающих создание необходимых условий для развития растений на ранее непригодных для сельскохозяйственного использования избыточно увлажненных площадях.

На избыточно-увлажненных почвах наиболее важным мелиоративным мероприятием является осушение.

Расчет осушительных систем базируется на гидрологических основах, которые разрабатываются на основании многолетних данных гидрометрических измерений, проведенных в речных бассейнах. Однако вследствие проведения гидро- и агромелиоративных работ в режиме стока часто происходят существенные изменения.

Если расчеты основываются на данных по стоку с неосушенных бассейнов, то нет уверенности в том, что проектируемые мероприятия дадут ожидаемые результаты и регулирование водно-воздушного режима будет достаточно рациональным и эффективным. Это обстоятельство указывает на пеобходимость изучения изменений в водном режиме, обусловленных мелиоративными работами.

Количественная оценка влияния осушения на режим стока является весьма сложной задачей вследствие отсутствия данных специальных наблюдений. В натуре невозможно отыскать водосборы, которые отличались бы только степенью осушения, а все остальные их характеристики, такие как рельеф, водопроницаемость почв, растительный покров и т. д., были бы идентичными. Поэтому непосредственное сравнение стока с осушенных и неосушенных бассейнов не может дать удовлетворительного ответа на данный вопрос, и анализ влияния осушения на сток следует производить параллельно с изучением влияния на режим стока других физико-географических факторов. Если будет выяснено влияние отдельных факторов на режим стока и станет известным изменение этих факторов под действием осушения, то можно будет получить представление и о влиянии на сток осушения. На этом основании нами была сделана попытка проанализировать влияние осушения и некөторых других факторов на режим среднего годового и минимального стока в почвенно-климатических условиях Эстонской ССР. 


\section{Влияние осушения на режим среднего годового стока}

Определение среднего годового стока за многолетний период имеет особое значение для гидрологических расчетов, так как средний годовой сток является одной. из основных гидрологических характеристик рассматриваемого района.

Размер испарения и стока зависит не только от климатических факторов (осадки, температура воздуха, скорость ветра, дефицит влажности воздуха и т. д.), а также от ряда физико-географических условий, таких как рельеф, геологическое строение, характер почвенного и растительного покрова, степень канализации бассейна и т. д. С влиянием всех этих факторов следует считаться при проведении гидрологических расчетов.

Вопрос об испарении и стоке с речных бассейнов рассмотрим сначала исходя из гидрометеорологических данных по двум соседним бассейнам двух магистральных каналов - Вяо-оя и Лейвайыги.

Бассейн магистрального канала Вяо-оя расположен на известняке нижнесилурийского яруса с водоупорными глинистыми прослойками между

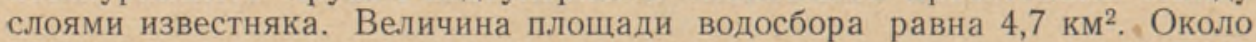
$30 \%$ площади водосбора подвержено временному переувлажнению. Подземного отвода воды с водосбора не замечается. Толщина почвенного горизонта над коренными породами (известняком) составляет в среднем около 50 см. Открытые поля и пастбища с маломощными почвами (около 20 см) над известняком составляют $35 \%$ всей площади бассейна, а $65 \%$ ее занято сенокосом, покрытым редким кустарником.

Бассейн магистрального канала Лейвайыги расположен к юго-востоку от бассейна Вяо-оя. Расстояние между центрами обоих бассейнов около 16 км. Физико-географические условия в бассейне Лейвайыги значительно отличаются от условий в бассейне Вяо-оя. Коренные породы нижнесилурийского известняка здесь покрыты более мощным (толщиной в несколько метров) слоем четвертичных отложений, состоящих из суглинистой основной морены и торфа. Величина площади бассейна равна

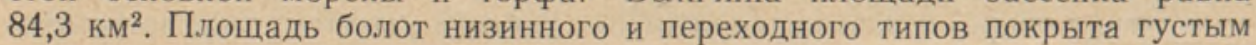
кустарником и составляет $53,7 \%$ от общей площади бассейна. $18,8 \%$ болот осушено и освоено. Осушенные площади покрыты большей частью густыми (через 50-100 м) лесными полосами. 16\% площади бассейна за: нято сенокосами с деревьями и кустарником; 17,4\% находится под лесом, а открытые поля составляют лишь $12,9 \%$ всей площади бассейна.

Количество осадков в обоих бассейнах почти равное.

Величина испарения с этих бассейнов вычислена по уравнению водного баланса

$$
z=x-y \pm \Delta w
$$

где $z$ - испарение, $x$ - осадки, $y$ - сток и $\Delta w-$ изменение запаса воды в водосборе.

Запасы $w$, которые принимают участие в кругообороте воды, разделены на две части: $\omega$-объем воды, стекающей в водоприемник, и $u$-объем воды, испаряющейся с водосборной площади, причем изменение объема

$$
\Delta w=\Delta \omega+\Delta u \text {. }
$$

Разность между запасами $\Delta \omega$, которые стекают за счет осадков предыдущего периода времени, и запасами, которые не успели стечь, найдена с помощью линий спада гидрографов. Линия спада представляет собой часть гидрографа, соответствующую периоду, когда отсутствует приток от осадков и талых вод. В период засухи сток происходит только за счет запасов, и интеграл кривой спада представляет собой объем запасов воды, сте- 
кающей с водосбора. Общий объем запасов воды, регулирующих сток с водосбора в определенный момент времени, определяется площадью, образуемой линией спада, соответствующей этому моменту ординатой гидрографа и точкой пересечения продолжения линии спада с нулевой линией.

Изменение запасов воды $\Delta \omega$ за счет стока представляет собой разницу площадей кривых спада в гидрографе в начале и конце периода.

Для определения $\Delta u$ - изменения запасов расходуемой на испарение и транспирацию почвенной влаги - были использованы измерения колебания уровня грунтовых вод и влажности почвы. По измерениям, произведенным в бассейне Вяо-оя, где уровень грунтовых вод залегает близко к поверхности почвы (менее 1 м), удалось установить связь между изменением объема почвенной влаги $\Delta u$ и колебанием уровня грунтовых вод $\Delta h$. Эта зависимость может быть выражена следующей формулой:

$$
\Delta u=0,13 \Delta h \text {. }
$$

Допуская, что при более низком наблюденном уровне грунтовых вод 1,01 м запас активной, т. е. доступной корням растений и принимающей участие в кругообороте, почвенной влаги равен примерно 15 мм, а максимальный запас при совпадающем с поверхностью почвы уровне грунтовых вод равен $0,13 \cdot 1010+15=146,3$ мм, мы можем для определения запаса активной влаги $u$ в бассейне Вяо-оя применить следующую формулу:

$$
u=146,3-0,13 h,
$$

где $u$-объем активной влаги в бассейне Вяо-оя в мм,

$h$ - расстояние уровня грунтовых вод от поверхности почвы в мм.

На основании данных измерения осадков $x$, стока $y$, изменения стекающих запасов $\Delta \omega$ и изменения запасов почвенной влаги $\Delta u$ можно из уравнения водного баланса найти величину испарения в бассейне Вяо-оя за короткие периоды, например за отдельные месяцы теплого сезона.

Найденные величины испарения в мае, июне, июле и августе - $z_{n}$ связаны с месячной суммой среднесуточного дефицита влажности воздуха $D_{n}$ и средним объемом активной (испаряющейся и транспирируемой) почвенной влаги $u_{n}$ на основании преобразованной формулы испарения Э. М. Ольдекопа, имеющей следующий вид:

$$
z_{n}=D_{n} \text { th } \frac{u_{n}}{D_{n}}
$$

где th - символ гиперболического тангенса.

Для определения среднемесячного объема влаги $u_{n}$ сначала было взято среднее из количества почвенной влаги в начале месяца $-\Sigma \Delta u_{n-1}$ (сумма $\Delta u$ за предыдущие месяцы) и количества ее в конце месяца $-\Sigma \Delta u_{n-1}+$ $\left.+x_{n}-y_{n}-\Delta \omega_{n}-z_{n}\right)$,

или

$$
u_{n}=\Sigma \Delta u_{n-1}+1 / 2\left(x_{n}-y_{n}-\Delta \omega_{n}\right)-1 / 2 z_{n} .
$$

Таким образом, $z_{n}$ может быть выражено следующим образом:

$$
z_{n}=D_{n} \text { th } \frac{\Sigma \Delta u_{n-1}+1 / 2\left(z_{n}-y_{n}-\Delta \omega_{n}\right)-1 / 2 z_{n}}{D_{n}} .
$$

Если обозначим

$$
D_{n} \text { th } \frac{\Sigma \Delta u_{n-1}+1 / 2\left(x_{n}-y_{n}-\Delta \omega_{n}\right)}{D_{n}}=z_{1 n},
$$


го значение $z_{1 n}$ будет явно бо́льшим, чем $z_{n} ; z_{1 n}$ может превысить $z_{n}$ до полутора раза. Поэтому для $z_{n}$ можно написать (с ошибкой не более $5 \%$ ) формулу следующего вида:

$$
z_{n}=D_{n} \text { th } \frac{\Sigma \Delta u_{n-1}+1 / 2\left(x_{n}-y_{n}-\Delta \omega_{n}\right)-1 / 3 z_{1 n}}{D_{n}},
$$

где

$$
z_{1 n}=D_{n} \text { th } \frac{\Sigma \Delta u_{n-1}+1 / 2\left(x_{n}-y_{n}-\Delta \omega_{n}\right)}{D_{n}} .
$$

Однако расчеты испарения по этой формуле дают уменьшенные результаты по сравнению с данными наблюдений. Поэтому формула $z_{n}$ требует введения поправки. Введение перед $D_{n}$ поправочного коэффициента более единицы является необоснованным, так как максимальное испарение $\left(z_{\max }=D_{n}\right)$ вряд ли может быть больше дефицита влажности воздуха. Поэтому поправку следует ввести в вычисление объема почвенной влаги.

Действительно, испарение после дождя, с мокрой поверхности почвы и растительного покрова происходит интенсивнее, чем в бездождный период. Следовательно, испарение из осадков данного месяца, или вернее, из разности осадки минус сток $\left(x_{n}-y_{n}-\Delta \omega_{n}\right)$ происходит интенсивнее, чем из запасов почвенной влаги предыдущего периода. Расчеты показывают, что если при вычислении среднемесячного объема почвенной влаги разность осадки минус сток для данного месяца принимать в расчет не в виде полусуммы $1 / 2\left(x_{n}-y_{n}-\Delta \omega_{n}\right)$, а в полном объеме $\left(x_{n}-y_{n}-\Delta \omega_{n}\right)$, то в таком исправленном виде формула испарения

$$
z_{n}=D_{n} \text { th } \frac{\Sigma \Delta u_{n-1}+x_{n}-y_{n}-\Delta \omega_{n}-1 / 3 z_{1 n}}{D_{n}},
$$

где

$$
z_{1 n}=D_{n} \text { th } \frac{\Sigma \Delta u_{n-1}+x_{n}-y_{n}-\Delta \omega_{n}}{D_{n}},
$$

дает удовлетворительные результаты.

Максимальное расхождение в размерах испарения по отдельным летним месяцам, найденного по водному балансу и вычисленного по формуле, не превышает в бассейне Вяо-оя 25,3 мм; среднее арифметическое расхождение равно 7 мм и среднее квадратичное 10,3 мм.

В холодный период года, когда интенсивность испарения в большей части зависит от дефицита влажности воздуха, величина испарения с водосборов была определена на основании данных водного баланса в бассейне Вяо-оя и была равна в сентябре

а с октября по апрель

$$
z_{\mathrm{IX}}=0,60 D_{\mathrm{IX}}
$$

$$
z_{\mathrm{X}-\mathrm{IV}}=0,40 D_{\mathrm{X}-\mathrm{IV}}
$$

где $z_{\mathrm{x}-\mathrm{IV}}$ - сумма испарения за месяцы холодного периода в мм и

$D_{\mathrm{x}-\mathrm{IV}}$ - сумма среднесуточных величин дефицита влажности воздуха за месяцы холодного периода в мм.

По приведенным выше формулам оказалось возможным вычислить величину испарения и изменения объема активной почвенной влаги в бассейне Лейвайыги, где не имелось данных измерения почвенной влаги и данных об уровне грунтовых вод. 
Результаты вычислений показали, что в бассейне Лейвайыги среднегодовая суммарная величина испарения на 26 мм, или $8 \%$, и средний максимальный объем активной почвенной влаги на 23 мм меньше, чем в бассейне Вяо-оя.

Можно предполагать, что приведенные результаты вычислений находятся в пределах точности расчета. Для контроля они были сопоставлены с величинами осадков и стока в осенний период, в год с обильными осенними осадками после засушливого лета. Было установлено, что объем почвенной влаги в бассейне Лейвайыги всегда пополняется осадками быстрее, чем в бассейне Вяо-оя. Например, после засушливых лета и осени 1938 года в октябре в бассейне Вяо-оя из суммы осадков 118,8 мм образовался сток в 17,1 мм, с учетом запасов, стекающих в виде потока грунтовых вод, а на пополнение запасов почвенной влаги и испарение осталось 101,7 мм. В бассейне же Лейвайыги соответствующие числа составляют 129,3 $-46,8=82,5$ мм, т. е. для пополнения запасов почвенной влаги и испарения здесь потребовалось на 19,2 мм меньше осадков, чем в бассейне Вяо-оя. В следующем, довольно дождливом месяце - ноябре особого изменения в запасах почвенной влаги в обоих бассейнах не наблюдалось.

Так как дождевые осадки, как и сток во время маловодья, измеряются в обоих бассейнах примерно с одинаковой точностью, то приведенные контрольные данные являются доказательством того, что изменение активной почвенной влаги и величины летнего и годового суммарного испарения в бассейне Вяо-оя действительно на 20-26 мм больше, чем в бассейне Лейвайыги.

Влагоемкость почвы болотистого ба́ссейна Лейвайыги значительно больше, чем в бассейне Вяо-оя, где маломощные почвы часто страдают от засухи. Несмотря на это, изменение активной почвенной влаги в первом бассейне меньше, чем во втором. Следовательно, увеличение испарения в бассейне Вяо-оя не может быть связано с влагоемкостью почвы.

Растительный покров на маломощных почвах в бассейне Вяо-оя слабее и, очевидно, транспирирует меньше влаги, чем в бассейне Лейвайыги.

Бассейн магистрального канала Лейвайыги расположен немного южнее бассейна Вяо-оя, и увеличение солнечной радиации в бассейне Лейвайыги должно влиять в направлении увеличения испарения, а не уменьшения его.

Из приведенного описания водосборов следует, что бассейн Вяо-оя является значительно более открытым, т. е. более легко продуваемым, чем бассейн Лейвайыги, где открытые поля занимают лишь $13 \%$ водосбора, а остальная часть покрыта лесом и густым кустарником. Поэтому очевидной причиной уменьшения испарения в бассейне Лейвайыги может служить защищенность поверхности почвы от прямой солнечной радиацин, а также уменьшение силы ветра и обмена влажных воздушных масс в приземном слое водосбора.

Непосредственные измерения влажности воздуха в бассейне Лейваӥыги показали, что средние годовые величины дефицита влажности воздуха на защищенном участке на 8 -9\% меньше, чем на слабо защищенном участке Таллинской метеорологической станции, расположенной вблизи бассейна Вяо-оя.

Величина дефицита влажности воздуха по карте, составленной по данным наблюденй расположенных на открытых участках метеорологических станций, в бассейне Лейвайыги оказывается на $5 \%$ больше, чем в бассейне Вяо-оя. Таким образом, влияние микроклиматических факторов привело в общем к уменьшению величины дефицита влажности воздуха в 5ассейне Лейвайыги на $14 \%$. 
Для дальнейшего изучения влияния различных условий в водосборе на режим стока были вычислены годовые суммы испарения по осадкам и дефициту влажности воздуха на всей территории Эстонской ССР. Вычисление велось по формуле Э. М. Ольдекопа, имеющей следующий вид:

$$
z=z_{\max } \text { th } \frac{x}{z_{\max }},
$$

где

$$
z \text { - годовая сумма испарения в мм, }
$$

$z_{\max }$ - величина максимального испарения в мм,

$x$ - сумма годовых осадков в мм,

th - символ гиперболического тангенса,

$z_{\max }=a d$.

причем $a$ - коэффициент, оценивающий влияние распределения летних осадков на размер испарения, н

$d$ - среднегодовая величина дефицита влажности воздуха в мм.

Расчеты были проведены за период с 1948 по 1951 год, так как за это время имелись наиболее подробные данные гидрометрических наблюдений. Размер коэффициента $\alpha$ за этот период был подсчитан по материалам водного баланса как средний для 15 основных бассейнов; получено $\alpha=247$.

Зная величину $а$, мы вычислили размеры испарения и стока на основании данных об осадках и дефиците влажности воздуха.

Разность между фактически наблюденным стоком в гидрометрических створах и вычисленным по климатическим данным стоком, очевидно, должна характеризовать влияние различных почвенно-геологических и геоботанических условий в водосборах на. величину годового стока.

Корреляция разностей наблюденного и вычисленного годового стока с факторами, влияющими на величину стока, дала следующую зависимость:

$$
\Delta y=0,80 c+15,7 q_{95 \%}-51,4
$$

с общим коэффициентом корреляции $R=0,81$.

Здесь $\Delta y-$ разность между фактически наблюденным средним годовым стоком и стоком, вычисленным по климатическим данным, в мм,

$c$ - процент избыточно увлажненных земель (болот, заболоченных минеральных земель с лесо-кустарниковым покровом),

$q_{95 \%}$ - среднесуточный сток с обеспеченностью $95 \%$ (средний минимальный сток) в л/сек/км².

Из приведенной формулы следует, что на болотах и заболоченных землях с лесо-кустарниковым покровом величина годового стока повышается, как это отмечалось выше. При полной заболоченности бассейна увеличение годового стока может доходить до 80 мм, или $30 \%$ средней величины стока. Средняя годовая сумма стока увеличивается, кроме того, с увеличением среднего минимального стока $c_{95 \%}$, оценивающего водопроницаемость грунтов в водосборе. При водопроницаемых грунтах атмосферные осадки легко инфильтрируются в нижние слои, откуда при сухой поверхности почвы испаряются слабее, чем при более водонепроницаемых влажных почвах.

Последняя формула пригодна и для оценки влияняя осушения болот на величину годового стока.

Можно предполагать, что испарение увеличивается при осушении болотных массивов, так как благодаря этому создаются открытые поля с обильным растительным покровом, величина испарения с которых должна приближаться к испарению с водосборов, покрытых открытыми полями со средними по механическому составу почвами, где процент заболочен- 
ности равен нулю. В этом случае можно ожидать увеличения испарения и уменьшения годового стока приблизительно на 80 мм.

Однако не всегда наличие болот в водосборе влияет в направлении увеличения стока. Гидрометрические наблюдения в бассейне Лейвайыги и в бассейнах болотной станции Тоома Управления гидрометслужбы ЭССР показывают, что суммарный годовой сток с неосушенных бассейнов может быть также меньшим, чем с осушенных. Такое влияние замечается в отношении малых водосборов на краевых участках болот, где постоянный приток грунтовых вод увлажняет поверхность болот, что способствует увеличению испарения. При осушении таких бассейнов уменьшается испарение с поверхности болот и увеличивается транспирация растительного покрова с освоенных под сельскохозяйственные культуры участков. Таким образом, величина годового стока может здесь изменяться меньше, чем при осушении центральных частей болотных массивов.

\section{Влияние осушения на режим минимального стока и распределение суточных расходов}

Гидрометрические данные показывают, что минимальный сток, характеризующий запасы воды, регулирующие сток с водосборов, на болотных бассейнах имеет малую величину. Таким образом, болота не оказывают значительного регулирующего влияния на распределение суточного стока (исключая максимальные суточные расходы с обеспеченностью менее $5 \%$ ).

После осушения и освоения болот обычно не замечается увеличения минимального стока, так как сток с осушительных систем за время вегетационного периода и холодного зимнего сезона понижается до нуля. Следовательно, после осушения не ожидается (в общем случае) увеличенной зарегулированности или уменьшенной вариации распределения суточного стока.

Особого увеличения вариации суточного стока после осушения тоже не следует ожидать, так как запасы воды, регулирующие сток и характеризующие минимальный сток, были и остаются малыми величинами до и после осушения.

Из этого общего положения могут быть исключения, в частности при осушении краевых болотных участков с притоком грунтовых вод из вышележащих водопроницаемых слоев. До осушения, когда приточные грунтовые воды разливаются по поверхности болот и затрачиваются на испарение, минимальный сток с болотных участков может быть равным нулю. После осушения, когда поток грунтовых вод перехватывается ловчими канавами, потери влаги на испарение с грунтовых вод значительно уменьшаются и минимальный сток может увеличиться.

Ннститут мелиорации и освоения осушенных земель Академии наук Эстонской ССР

Поступила в редакцию $1 \times 1954$ 